\title{
ASPECTOS SOCIOECONÔMICOS E O CULTIVO DE PLANTAS MEDICINAIS EM QUINTAIS AGROFLORESTAIS URBANOS (QAF) NO MUNICÍPIO DE BREU BRANCO, PARÁ, BRASIL
}

Vanessa Maria Silva da Cruz'; Alexandre Leão Gonçalves ${ }^{1}$; Jamerson Rodrigo dos Prazeres Campos²; Alisson Rodrigo Souza Reis ${ }^{2}$.

${ }^{1}$ Discente de Engenharia Florestal; Universidade Federal do Pará;

(vanessa.msc@hotmail.com)

${ }^{2}$ Docente da Faculdade de Engenharia Florestal; Universidade Federal do Pará

Recebido em: 08/04/2017 - Aprovado em: 10/06/2017 - Publicado em: 20/06/2017

DOI: 10.18677/EnciBio 2017A15

\section{RESUMO}

O presente estudo teve o objetivo de avaliar a ocorrência de plantas medicinais em quintais agroflorestais urbanos no município de Breu Branco-PA, fazendo um comparativo do cultivo dessas plantas entre dois bairros com características socioeconômicas distintas. Para isso, realizou-se entrevistas com os proprietários dos quintais em dois bairros, com o auxílio de um questionário buscando saber 0 perfil socioeconômico dos entrevistados, bem como a parte da planta utilizada, o modo de consumo e a indicação de uso das espécies. As plantas foram identificadas em campo, com o auxílio do proprietário de cada quintal, além disso, tiveram um registro fotográfico detalhado e foram comparadas com exsicatas das plataformas Flora do Brasil e MOBOT. Registrou-se 333 indivíduos, divididos em 36 famílias e 60 espécies. A parte da planta mais utilizada é a folha (79\%), e o modo de preparo mais frequente é o chá (69\%). A espécie com maior número de citações foi a Babosa (FR $\%=14)$. Quanto às indicações de uso, destacou-se a gripe $(14 \%)$ e dores em geral (12\%). Portanto, os quintais agroflorestais urbanos de Breu Branco dispõem de uma quantidade significativa de plantas medicinais, preparadas de diferentes maneiras e com variedade de indicações. A população com menor grau de escolaridade e renda, maior número de pessoas no grupo familiar, e que residem em casas predominantemente de madeira, são as que mais cultivam essas espécies. Além disso, as mulheres são as principais responsáveis pela manutenção e cuidados com o cultivo.

PALAVRAS-CHAVE: consumo, subsistência, tradição.

\section{SOCIOECONOMIC ASPECTS AND THE CULTIVATION OF MEDICINAL PLANTS IN AGROFORESTRY BACKYARDS URBAN IN THE MUNICIPALITY OF BREU BRANCO, PARÁ, BRAZIL}

\begin{abstract}
The present study aimed to evaluate the occurrence of medicinal plants in backyards urban agroforestry in the municipality of Breu Branco-PA, making a comparative study of the cultivation of these plants between two neighborhoods with socioeconomic characteristics. For this reason, we carried out interviews with the owners of backyards in two neighborhoods, with the help of a survey seeking to know
\end{abstract}


the socioeconomic profile of the interviewees, as well as the part of the plant used, the mode of consumption and the indication of use of species. The plants were identified in the field, with the help of the owner of each yard, in addition, had a photographic record detailed and were compared with specimens of the platforms Flora of Brazil and MOBOT. There were 333 individuals, divided into 36 families and 60 species. The part of the plant used most is the leaf $(79 \%)$, and the mode of preparing more frequently is tea $(69 \%)$. The species with the highest number of citations was the Aloe Vera $(\mathrm{FR} \%=14)$. As to the indications for use, emphasis was given to the flu $(14 \%)$ and pain in general $(12 \%)$. Therefore, the Agroforestry backyards city of Breu Branco has a significant amount of medicinal plants, prepared in different ways and with a variety of indications. The population with lower educational level and income, the greater number of people in the family group, and who live in homes predominantly of wood, are the most cultivate these species. In addition, women are the primary responsibility for the maintenance and care with the cultivation.

KEYWORDS: Consumption, livelihood, tradition.

\section{INTRODUÇÃO}

Desde a pré-história o homem procurou aproveitar os princípios ativos existentes no ambiente natural, mesmo de modo empírico e intuitivo, baseado em descoberta ao acaso (BERG, 2010). A utilização de plantas medicinais faz parte da cultura popular devido as diversas potencialidades terapêuticas que apresentam, e o uso dessas espécies também está associado à aplicação do etnoconhecimento que segue diversas técnicas alternativas (SANTOS \& SANTOS, 2012).

No Brasil, o consumo de plantas medicinais tem como característica o uso empírico, baseado no senso comum com poucas comprovações científicas (CAETANO et al., 2015). As plantas medicinais representam a principal forma de tratamento de doenças para a maioria da população com baixa renda na região amazônica, devido às influências culturais e ao custo dos produtos farmacêuticos (VEIGA \& SCUDELLER, 2015).

De acordo com MESSIAS et al. (2015) parte da população brasileira encontra nas plantas medicinais a única fonte de recursos terapêuticos, e isso ocorre tanto pela riqueza da biodiversidade, como também pelo baixo poder aquisitivo da população. A Organização Mundial de Saúde (OMS) estima que cerca de $80 \%$ da população mundial depende das plantas para o cuidado com a saúde (BRASIL, 2006).

Dentro deste contexto estão inseridos os quintais agroflorestais (QAFs), que são áreas situadas ao redor da casa, no meio rural ou urbano, onde se cultivam plantas com a finalidade de oferecer complementação nutricional, medicamentos, e muitas vezes, esses espaços também são utilizados para a criação de animais domésticos ou domesticados de pequeno porte (SIVIEIRO et al., 2012). Devido aos benefícios e a tradição de uso, a maior parte dos proprietários de quintais agroflorestais urbanos dão preferência ao cultivo de espécies para fins medicinais, que geralmente são utilizadas para tratar enfermidades no âmbito familiar (FREITAS et al., 2012).

Além de serem provedores de plantas que auxiliam na saúde e subsistência das famílias, os QAFs possuem importantes funções ecológicas, uma vez que contribuem para a conservação de plantas e variabilidade genética, apresentando-se como um importante banco de germoplasma, e dessa maneira esses 
agroecossistemas se constituem como sistemas sustentáveis com maior resistência a doenças e pragas (FLORENTINO et al., 2007).

Desse modo, este trabalho teve o objetivo de avaliar a ocorrência de plantas medicinais em quintais agroflorestais urbanos no município de Breu Branco-PA, fazendo um comparativo do cultivo dessas plantas entre dois bairros com características socioeconômicas distintas.

\section{MATERIAL E MÉTODOS}

A pesquisa foi desenvolvida na zona urbana do município de Breu Branco (latitude $04^{\circ} 04^{\prime} 04^{\prime \prime S}$ e longitude $49^{\circ} 38^{\prime} 13^{\prime \prime O}$ ), região sudeste do estado do Pará. O município está a cerca de $419 \mathrm{Km}$ da capital do estado, e juntamente com outros seis municípios, está inserido na região de integração do lago de Tucuruí (FAPESPA, 2014). De acordo com dados do Instituto Brasileiro de Geografia Estatística - IBGE, Breu Branco possui um território de $3.941,911 \mathrm{~km}^{2}$, com população estimada de 62.737 mil habitantes, e densidade demográfica de 13,32 $\mathrm{hab} / \mathrm{km}^{2}$ (IBGE, 2016).

O território breuense possui clima tropical úmido, de acordo com a classificação de Köeppen, do subtipo Am, com índice pluviométrico anual de 2000 $\mathrm{mm}$. Entre os meses de julho e setembro registra-se a ocorrência de um leve período de estiagem, tendo precipitações inferiores a $50 \mathrm{~mm}$ e temperatura média de $26^{\circ} \mathrm{C}$ (PDRS, 2013). Quanto à vegetação, predomina o tipo Floresta Ombrófila Densa, com subtipo Ombrófila Aluvial, tendo também a ocorrência de Floresta Ombrófila mesclada com vegetação secundária (BREU BRANCO, 2006).

Para a escolha dos bairros a serem pesquisados, consultou-se o Plano Diretor de Breu Branco a fim de obter informações sobre a idade de fundação dos bairros, e em passeio pelos bairros, foram observadas as características de arborização nos quintais e a distância dos mesmos em relação ao centro da cidade. Isso foi feito para realizar um comparativo da utilização de plantas medicinais entre bairros com características distintas.

Desse modo, escolheram-se os bairros Bela Vista (características: antigo, pouca arborização nos quintais, e próximo ao centro) e Novo Horizonte (características: recente em relação ao Bela Vista, muita arborização nos quintais, e distante do centro) (BREU BRANCO, 2006). A pesquisa foi realizada no mês de maio de 2016 e guiada pelo mapa cartográfico da cidade, que indicou os limites das quadras e dos bairros pesquisados (Figura 1). 


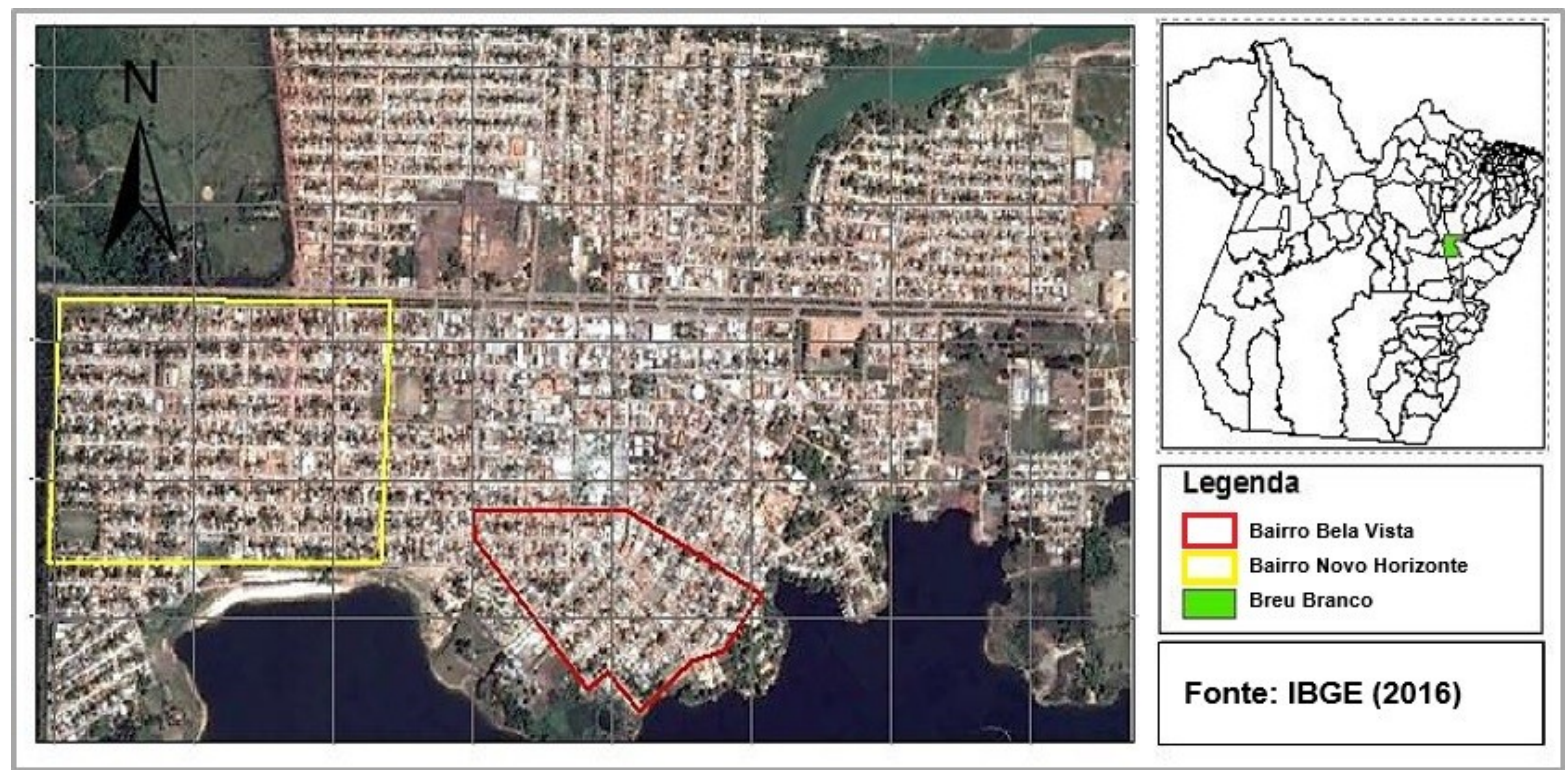

FIGURA 1. Localização dos bairros pesquisados no território de Breu Branco - PA. Fonte: IBGE (2016)

Nos bairros pesquisados, selecionaram-se aleatoriamente dois quintais em cada quadra, conforme o exemplificado na figura 2, repetindo-se em todas as quadras de ambos os bairros.



FIGURA 2. Representação da coleta de dados.

Fonte: autores

Em todas as visitas, realizou-se entrevistas com os proprietários dos quintais, utilizando um questionário semiestruturado com cinco perguntas abertas e 10 perguntas fechadas. O questionário buscou informações em relação ao perfil socioeconômico dos entrevistados (sexo, idade, escolaridade, valor e origem da renda familiar, moradia em casa de barro, madeira ou alvenaria), e sobre a parte da planta utilizada, o modo de consumo e a indicação de uso de cada espécie. Vale ressaltar que o levantamento dos dados foi realizado com o consentimento prévio dos proprietários dos quintais.

As plantas citadas como sendo de uso medicinal foram identificadas ainda em campo, contando com o auxílio do proprietário de cada quintal. Em razão de serem corriqueiramente cultivadas na região, a maioria das plantas medicinais foi de fácil reconhecimento no local.

Algumas espécies tiveram um registro fotográfico detalhado, e em seguida foram comparadas com exsicatas disponíveis nas plataformas Flora do Brasil (FORZZA et al., 2016) e Missouri Botanical Garden (MOBOT, 2016). Consultaram-se 
também algumas chaves de identificação (SOUZA \& LORENZI, 2012; LORENZI, 2014), e realizou-se um levantamento bibliográfico em literaturas relevantes no reconhecimento das espécies (BERG, 2010; GONÇALVES \& LORENZI, 2011; MARTINS, 2012). Adotou-se o APG III (THE ANGIOSPERM PHYLOGENY GROUP, 2009) como sistema taxonômico para esse trabalho.

Após o levantamento dos dados e a identificação das plantas, calculou-se a frequência relativa (FR) das espécies utilizando a metodologia de MUELLERDOMBOIS \& ELLENBERG (1974). O cálculo e a sistematização dos dados foram executados com o auxílio do software Excel 2013.

\section{RESULTADOS E DISCUSSÃO}

No total foram visitados 158 quintais agroflorestais, sendo 116 no bairro Novo Horizonte e 42 no Bela Vista. O Bairro Novo Horizonte teve mais visitações devido ter maior extensão no município em relação ao Bela Vista.

A pesquisa identificou 333 indivíduos, divididos em 36 famílias distintas e 60 espécies. Dentre essas famílias botânicas, destacaram-se: Lamiaceae (8 spp.), Zingiberaceae (5 spp.), Euphorbiaceae (5 spp.), Asteraceae (3 spp.), e Crassulaceae (3 spp.). De maneira semelhante, FREITAS et al. (2012) estudando a ocorrência de plantas medicinais nos quintais agroflorestais de São Miguel-RN, identificaram o cultivo de 60 espécies pertencentes a 35 famílias. Os autores também verificaram Lamiaceae como a família com o maior número de espécies (5 spp.). O mesmo resultado sobre essa família botânica foi registrado por FERREIRA \& SABLAYROLES (2009) nos quintais agroflorestais da Reserva Extrativista TapajósArapiuns, Pará.

As plantas medicinais cultivadas nos QAFs de Breu Branco são predominantemente herbáceas de pequeno porte. Corroborando com esses resultados, SOUZA \& LORENZI (2012) explicam que as espécies da família Lamiaceae são representadas em sua maioria por ervas, principalmente pelas aromáticas, sendo que no território brasileiro encontram-se cerca de 38 gêneros e 500 espécies dessa família.

A forma de uso das espécies medicinais apresentou-se bastante diversificada, de maneira que os cultivadores não seguem um padrão quanto ao modo de preparo dos remédios caseiros utilizando uma mesma planta, cada um possui uma maneira peculiar de preparar e consumir os fitoterápicos, de acordo com a sua cultura e/ou crença. Dentre as diferentes partes da planta que se utiliza, a folha foi a mais citada, e o chá se destacou como o modo de consumo mais recorrente (figura 3).

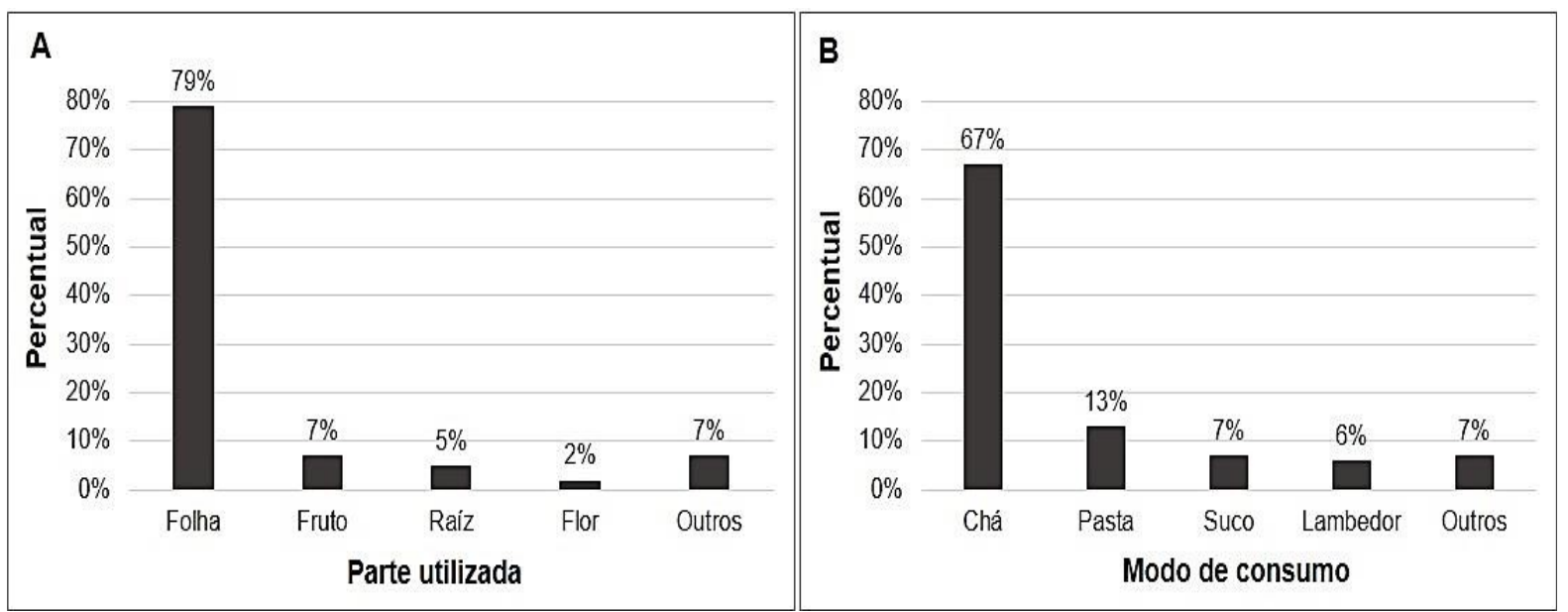


FIGURA 3. Percentual de uso das partes da planta (A) e de modos de consumo (B).

Através dos resultados expostos na figura 3 é possível inferir que apesar de os cultivadores de plantas medicinais não seguirem um padrão de preparo de consumo desses remédios caseiros, a forma de preparo retrata um conhecimento tradicional empírico, de maneira que as enfermidades são tratadas de acordo com a orientação de familiares.

Nos quintais urbanos de Rio Branco, estado do Acre, SIVIERO et al. (2012) obtiveram resultados semelhantes aos desta pesquisa, no qual a parte da planta mais utilizada é a folha, e o chá é a forma de consumo com o maior número de citações pelos entrevistados. FREITAS et al. (2012) também constataram a folha como a parte da planta mais utilizada, seguida dos frutos e flores.

SANTOS \& SANTOS (2012) estudando o uso de plantas medicinais no âmbito da agricultura familiar, registraram resultados similares quanto ao modo de consumo (chá como o mais recorrente), e discrepantes em relação à parte da planta, verificando a casca como a mais utilizada. Já SILVA et al. (2015) constaram que os moradores da comunidade do Sítio Nazaré, no município de Milagres-CE, utilizam predominantemente as raízes para o preparo de seus remédios caseiros.

As espécies medicinais de maior frequência estão representadas na tabela 1.

TABELA 1. Plantas medicinais de maior ocorrência nos quintais agroflorestais urbanos de Breu Branco-PA.

\begin{tabular}{|c|c|c|c|c|c|c|c|}
\hline $\begin{array}{c}\text { Nome } \\
\text { popular }\end{array}$ & $\begin{array}{c}\text { Nome } \\
\text { científico }\end{array}$ & Família & $\begin{array}{c}\mathbf{N}^{\circ} \text { de } \\
\text { indivíduos }\end{array}$ & $\begin{array}{l}\text { FR } \\
(\%)\end{array}$ & $\begin{array}{c}\text { Parte } \\
\text { utilizada }\end{array}$ & $\begin{array}{l}\text { Modo de } \\
\text { consumo }\end{array}$ & Indicação \\
\hline Babosa & Aloe vera $\mathrm{L}$. & $\begin{array}{l}\text { Asphodel } \\
\text { aceae }\end{array}$ & 35 & 14 & Folha & Chá/pasta & $\begin{array}{l}\text { Cicatrizante de } \\
\text { ferimentos }\end{array}$ \\
\hline Boldo & $\begin{array}{c}\text { Plectranthus } \\
\text { barbatus Andre } \\
\text { ws }\end{array}$ & $\begin{array}{c}\text { Lamiace } \\
\text { ae }\end{array}$ & 26 & 10 & Folha & Chá & $\begin{array}{l}\text { Dores no } \\
\text { estômago e } \\
\text { fígado }\end{array}$ \\
\hline Mastruz & $\begin{array}{c}\text { Chenopodium } \\
\text { ambrosioides } \\
\text { L. }\end{array}$ & $\begin{array}{l}\text { Amarant } \\
\text { haceae }\end{array}$ & 22 & 11 & Folha & Suco & $\begin{array}{l}\text { Vermífugo/ } \\
\text { infecções }\end{array}$ \\
\hline Cidreira & $\begin{array}{l}\text { Lippia alba } \\
\text { (Mill) N. E. } \\
\text { Brown }\end{array}$ & $\begin{array}{l}\text { Verbenac } \\
\text { eae }\end{array}$ & 21 & 9 & Folha & Chá/pasta & Calmante/gripe \\
\hline Malvarisca & $\begin{array}{c}\text { Plectranthus } \\
\text { amboinicus } \\
\text { Lour. }\end{array}$ & $\begin{array}{l}\text { Lamiace } \\
\text { ae }\end{array}$ & 20 & 9 & Folha & Lambedor & $\begin{array}{c}\text { Dores na } \\
\text { garganta/gripe }\end{array}$ \\
\hline Alfavaca & $\begin{array}{c}\text { Ocimum } \\
\text { gratissimum L. }\end{array}$ & $\begin{array}{l}\text { Lamiace } \\
\text { ae }\end{array}$ & 19 & 10 & Folha & Chá/banho & $\begin{array}{c}\text { Gripe/ } \\
\text { inflamações }\end{array}$ \\
\hline Gengibre & $\begin{array}{l}\text { Zingiber } \\
\text { officinale } \\
\text { Roscoe }\end{array}$ & $\begin{array}{l}\text { Zingibera } \\
\text { ceae }\end{array}$ & 16 & 6 & $\begin{array}{c}\text { Folha/Rai } \\
z\end{array}$ & Chá & $\begin{array}{c}\text { Cólicas } \\
\text { menstruais/dor } \\
\text { es na garganta }\end{array}$ \\
\hline Hortelã & $\begin{array}{c}\text { Mentha spicata } \\
\text { L. }\end{array}$ & $\begin{array}{l}\text { Lamiace } \\
\text { ae }\end{array}$ & 15 & 6 & Folha & $\begin{array}{l}\text { Chá/lambe } \\
\text { dor }\end{array}$ & $\begin{array}{c}\text { Cólicas } \\
\text { menstruais/grip } \\
\mathrm{e}\end{array}$ \\
\hline $\begin{array}{l}\text { Capim } \\
\text { Santo }\end{array}$ & $\begin{array}{l}\text { Cymbopogon } \\
\text { citratus Stapf }\end{array}$ & Poaceae & 13 & 6 & Folha & Chá & $\begin{array}{l}\text { Calmante/ } \\
\text { vermífugo }\end{array}$ \\
\hline Romã & $\begin{array}{c}\text { Punica } \\
\text { granatum L. }\end{array}$ & $\begin{array}{c}\text { Punicace } \\
\text { ae }\end{array}$ & 13 & 8 & $\begin{array}{l}\text { Folha/Fru } \\
\text { to }\end{array}$ & Chá & $\begin{array}{l}\text { Dores na } \\
\text { garganta }\end{array}$ \\
\hline Arruda & $\begin{array}{c}\text { Ruta } \\
\text { graveolens L. }\end{array}$ & Rutaceae & 12 & 6 & Folha & $\begin{array}{l}\text { Chá/pasta/ } \\
\text { suco }\end{array}$ & $\begin{array}{c}\text { Cólicas } \\
\text { menstruais/dor } \\
\text { es na cabeça }\end{array}$ \\
\hline Pariri & $\begin{array}{c}\text { Arrabidaea } \\
\text { chica (Bonpl.) } \\
\text { Verl. }\end{array}$ & $\begin{array}{l}\text { Bignonia } \\
\text { ceae }\end{array}$ & 12 & 5 & Folha & Chá/pasta & Febre/anemia \\
\hline TOTAL & & & 224 & 100 & - & - & - \\
\hline
\end{tabular}


$\mathrm{FR}=$ Frequência Relativa (\%). 
Dentre os 333 indivíduos inventariados, a Babosa (Aloe vera L.) ocorreu 35 vezes. Registrou-se o cultivo de $A$. vera em 34 quintais, e em 23 foi relatada a indicação dessa planta como cicatrizante de ferimentos na pele. Outros entrevistados também a indicaram para o tratamento de dores no estômago, gastrite, e inflamações em geral.

De acordo com SOUZA \& LORENZI (2012), no Brasil as espécies do gênero Aloe estão entre as plantas mais comumente cultivas para fins terapêuticos, e em alguns casos também são utilizadas como ornamentais.

Em uma pesquisa sobre o uso de plantas medicinais com ênfase em pacientes oncológicos, no município de Lagarto-SE, CAETANO et al. (2015) também identificaram o Boldo (Plectranthus barbatus Andrews), a Cidreira (Lippia alba (Mill) N. E. Brown) e o Capim Santo (Cymbopogon citratus Stapf.) entre as espécies mais frequentemente cultivadas pela população dessa cidade.

FLOR \& BARBOSA (2015) relataram resultados distintos aos desta pesquisa, nos quais a Babosa (Aloe vera L.), o Mastruz (Chenopodium ambrosioides L.), a Cidreira (Lippia alba (Mill) N. E. Brown), a Alfavaca (Ocimum sp.), e o Gengibre (Zingiber officinale Roscoe) estão entre as espécies com poucas citações pelos moradores do bairro do sossego no distrito de Marudá-PA.

Os resultados desta pesquisa somados a outros observados, evidenciam que o cultivo de plantas medicinais é consideravelmente variado nas regiões do Brasil, de modo que a menor ou maior ocorrência de determinadas espécies é influenciada pelos benefícios terapêuticos conhecidos pela população local, tendo em vista a cultura construída a cerca dessas plantas.

Durante a pesquisa, observou-se que os entrevistados possuem o hábito de cultivar essas espécies em canteiros feitos diretamente no solo, ou suspensos (geralmente em quintais onde há criação de aves), visto que o cultivo dessas plantas separadamente facilita o combate a ervas daninhas e o manuseio no momento da colheita. SIVIEIRO et al. (2012) expõem que plantas medicinais exigem maiores cuidados quanto ao solo, luminosidade e intensidade de chuvas, por esse motivo, muitas vezes são cultivadas em canteiros juntamente com as hortaliças.

Quanto às indicações de uso, as mais citadas foram gripe (14\%), dores em geral $(12 \%)$, inflamações $(6 \%)$, calmante $(5 \%)$ e vermífugo $(3 \%)$, as outras 67 indicações tiveram um percentual baixo cada uma, mesmo assim somaram $60 \%$. Dentre as 60 espécies, 33 tiveram uma única indicação, seguidas por 7 espécies com duas indicações, 4 espécies com três indicações e 3 espécies com quatro indicações. As outras 13 espécies tiveram número de indicações variando entre cinco e dez.

FERREIRA \& SABLAYROLLES (2009) também registraram o tratamento de gripe como a principal indicação de uso. Na pesquisa de SANTOS \& SANTOS (2012) as plantas também foram indicadas, principalmente, para o tratamento de gripe, seguida por dores em geral (cabeça, estômago e garganta), e ferimentos.

De maneira semelhante, FREITAS et al. (2012) constataram a gripe com o maior número de citações dentre as indicações terapêuticas. Estes autores expõem ainda que, geralmente, a maior parte das plantas medicinais possui mais de uma indicação de uso, como no caso da Hortelã (Mentha arvensis L.), Arruda (Ruta graveolens L.), Malvarisca (Plectranthus amboinicus Lour.), Capim Santo (Cymbopogon citratus Stapf) e Babosa (Aloe vera L.).

A malvarisca (Plectranthus amboinicus Lour.) teve $100 \%$ das indicações para o uso no tratamento de dores na garganta e gripe. Em Vila Cachoeira, estado da Bahia, MOREIRA et al. (2002) relataram $P$. amboinicus com nome vernacular de 
hortelã-grosso, e tendo indicação contra problemas hepáticos. Dessa maneira, observa-se a diversificação de usos para uma mesma espécie no território brasileiro, e a variação de vernáculos de região para região, podendo ainda, ocorrer diferenças desses fatores em uma mesma região. Analisando as particularidades dos bairros, verificou-se que $78 \%$ do total de indivíduos inventariados foi registrado no bairro Novo Horizonte (média de 2,3 indivíduos por QAF) e $22 \%$ no bairro Bela vista (média de 1,7 indivíduos por QAF).

Vale ressaltar que $29 \%$ dos proprietários de quintais no bairro Bela Vista não cultivam plantas medicinais, e $23 \%$ não cultivam no Novo Horizonte, evidenciando uma média aproximada em ambos os bairros. Portanto, esses resultados juntamente com a média de indivíduos por quintal explicam que a maior extensão do bairro Novo Horizonte em relação ao outro pesquisado, não foi o fator determinante para a maior ocorrência de plantas medicinais no mesmo, mas sim o interesse de cultivo dos proprietários. A tabela 2 expõe o perfil socioeconômico dos entrevistados nos dois bairros investigados, em termos percentuais, e utilizando-se a média aritmética para alguns parâmetros.

TABELA 2. Perfil socioeconômico dos proprietários de QAFs urbanos de Breu Branco.

\begin{tabular}{|c|c|c|c|}
\hline \multirow{2}{*}{$\begin{array}{c}\text { Dados } \\
\text { socioeconômicos }\end{array}$} & \multirow{2}{*}{ Categorias } & \multicolumn{2}{|c|}{ Bairros } \\
\hline & & Novo Horizonte & Bela Vista \\
\hline \multirow{2}{*}{ Gênero (\%) } & Masculino & 42 & 33 \\
\hline & Feminino & 58 & 67 \\
\hline Idade (Média) & - & 47 & 49 \\
\hline \multirow{5}{*}{ Escolaridade (\%) } & Fundamental incompleto & 57 & 32 \\
\hline & Fundamental completo & 12 & 24 \\
\hline & Ens. médio incompleto & 9 & 18 \\
\hline & Ens. médio completo & 15 & 21 \\
\hline & Sem escolaridade & 9 & 7 \\
\hline Renda (Média) & - & 1,5 & 2,5 \\
\hline \multirow{6}{*}{ Origem da renda (\%) } & Aposentado & 45 & 36 \\
\hline & Autônomo & 19 & 34 \\
\hline & Emprego fixo & 15 & 25 \\
\hline & Programas do governo & 14 & 6 \\
\hline & Desempregado & 5 & 11 \\
\hline & Comerciante & 2 & 6 \\
\hline Grupo familiar (média) & - & 5 & 3 \\
\hline \multirow{2}{*}{ Tempo de moradia (\%) } & $>10$ anos & 44 & 62 \\
\hline & $\leq 10$ anos & 56 & 38 \\
\hline \multirow{2}{*}{ Tipo de residência (\%) } & Pred. Madeira & 56 & 31 \\
\hline & Pred. Alvenaria & 44 & 69 \\
\hline
\end{tabular}

Em ambos os bairros, a maioria dos entrevistados foi do sexo feminino, com idade média de 47 anos no Novo Horizonte e 49 no bairro Bela Vista. CAETANO et al. (2015) e FREITAS et al. (2012) também obtiveram resultados semelhantes em relação a predominância do gênero feminino. 
Concernente a esse resultado, OLIVEIRA \& LUCENA (2015) esclarecem que isso ocorre devido à maioria das mulheres de regiões interioranas permanecerem em casa, e serem responsáveis pelas tarefas do lar, tendo maior disponibilidade para cuidar do quintal e do cultivo de plantas.

Durante as entrevistas observou-se que existe uma relação entre idade e conhecimento sobre o uso e o cultivo das plantas medicinais, pois quanto maior a idade dos entrevistados, maior o grau de conhecimento sobre o uso dessas espécies. Isso se dá principalmente pelo acúmulo de experiência de vida, bem como por fatores culturais inerentes a essas pessoas.

Através da tabela 2 e da média de indivíduos por quintal, observa-se que as pessoas com menor grau de escolaridade (bairro Novo Horizonte) possuem maior preferência pelo cultivo de plantas medicinais. Esses resultados podem estar associados à tradição de uso dos fitoterápicos, que é passada dos pais para os filhos, perpassando por gerações, segundo o relato de $98 \%$ dos entrevistados.

FLOR \& BARBOSA (2015) também relataram que quanto menor o grau de instrução, maior é o cultivo e uso dos fitoterápicos. Já SIVIERO et al. (2012) constataram que a ocorrência de espécies medicinais independe do grau de escolaridade, diferindo do que ocorreu nos QAFs urbanos de Breu Branco.

Outra relação importante de se observar é o fato dos entrevistados com renda inferior e com maior número de pessoas no grupo familiar, plantarem mais frequentemente as espécies para fins medicinais. Com isso, notou-se que em ambos os bairros a renda familiar possui uma relação inversamente proporcional ao cultivo das plantas medicinais.

Dessa maneira, é possível inferir sobre a importância dos quintais agroflorestais como espaço de cultivo de plantas para a produção de remédios caseiros para as famílias de baixa renda, de modo que isso auxilia na despesa familiar, com a substituição do uso de produtos farmacêuticos pelos fitoterápicos.

Para OLIVEIRA \& LUCENA (2015), do ponto de vista social é de conhecimento geral que as camadas da população com menor renda e baixa escolaridade possuem conhecimentos básicos da medicina natural.

A relação inversamente proporcional também foi constatada no que se refere ao tipo de residência, nas casas predominantemente de madeira onde os proprietários possuíam menor poder aquisitivo, registrou-se maior número de plantas medicinais (Novo Horizonte), já nas residências predominantemente construídas em alvenaria inventariaram-se poucos indivíduos cultivados com a finalidade de produção de remédios caseiros (Bela Vista).

De acordo com o Plano Diretor de Breu Branco, o bairro Bela Vista foi um dos primeiros a ser fundado, sendo consideravelmente mais velho que o Novo Horizonte (BREU BRANCO, 2016). Apesar disso, os proprietários de quintais desse bairro cultivam poucas plantas medicinais, evidenciando que o tempo de fundação e moradia (tabela 2) foi inversamente proporcional ao cultivo de plantas medicinais.

\section{CONCLUSÃO}

Os quintais agroflorestais urbanos de Breu Branco-PA dispõem de uma quantidade significativa de plantas medicinais, que são preparadas de diferentes maneiras, destacando-se o chá, e possuem variedade de indicações para o tratamento de enfermidades, principalmente, gripe e dores em geral.

Os dados socioeconômicos evidenciaram que a população com menor grau de escolaridade e renda, maior número de pessoas no grupo familiar, e que residem em casas predominantemente de madeira, são as que mais cultivam espécies para 
a produção de remédios caseiros. Além disso, constatou-se que as mulheres são as principais responsáveis pela manutenção e cuidados com as plantas medicinais.

\section{REFERÊNCIAS}

ANGIOSPERM PHYLOGENY GROUP. An update of the angiosperm phylogeny group classification for the orders and families of flowering plants: APG II. Botanical Journal of the Linnean Society, v. 141, n. 4, p. 399-436, 2003. Disponível em: <http://dx.doi.org/10.1046/j.1095-8339.2003.t01-1-00158.x>. doi: 10.1046/j.1095-833 9.2003.t01-1-00158.x.

BERG, M. E. V. D. Plantas medicinais na Amazônia: contribuição ao seu conhecimento sistemático. v. 1. 3 ed. Belém; Museu Paraense Emílio Goeldi, 2010. $268 \mathrm{p}$.

BRASIL. A Fitoterapia no SUS e o Programa de Pesquisas de Plantas Medicinais da Central de Medicamentos. v. 1. 2 ed. Brasília: Ministério da saúde, 2006. 148 p.

BREU BRANCO. Plano diretor do município de Breu Branco. Prefeitura Municipal de Breu Branco, 2006. Disponível em: <http://www.seidurb.pa.gov.br/pdm/breu_bran co/Plano_Diretor.pdf>. Acesso em: 18 out. 2016.

CAETANO, N. L. B.; FERREIRA, T. F.; REIS, M. R. O.; NEO, G. G. A.; CARVALHO, A. A. Plantas medicinais utilizadas pela população do município de Lagarto- SE, Brasil - ênfase em pacientes oncológicos. Revista Brasileira de Plantas medicinais, Campinas, v. 17, n. 4, p. 748-756, dez. 2015. Disponível em: <http://dx. doi.org/10.1590/1983-084X/14_056>. doi: 10.1590/1983-084X/14_056.

FAPESPA. Diagnóstico Socioeconômico e Ambiental da Região de Integração Lago de Tucuruí. Fundação Amazônica de Amparo a Estudos e Pesquisas do Pará, 2014. Disponível em: <http://www.fapespa.pa.gov.br/sites/default/files/Regiao_Integr acao_Lago_de_Tucurui.pdf>. Acesso em: 15 dez. 2016.

FERREIRA, T. B.; SABLAYROLLES, M. das G. P. Quintais agroflorestais como fonte de saúde: plantas medicinais na Comunidade de Vila Franca, Reserva Extrativista Tapajós-Arapiuns, Pará. Revista Brasileira de Agroecologia, São Paulo, v. 4, n. 2, p. 59-68, nov. 2009. Disponível em: <http://www.aba-agroecologia.org.br/revistas/ind ex.php/rbagroecologia/article/view/8955/6269>. Acesso em: 9 nov. 2016.

FLOR, A. S. S. O.; BARBOSA, W. L. R. Sabedoria popular no uso de plantas medicinais pelos moradores do bairro do sossego no distrito de Marudá - PA. Revista Brasileira de Plantas medicinais, Campinas, v. 17, n. 4, p. 757-768, dez. 2015. Disponível em: <http://dx.doi.org/10.1590/1983-084X/14_064>. doi: 10.1590 /1983-084X/14_064.

FLORENTINO, A. T. N.; ARAÚJO, E. de L.; ALBUQUERQUE, U. P. de. Contribuição de quintais agroflorestais na conservação de plantas da Caatinga, Município de Caruaru, PE, Brasil. Revista Acta Botânica Brasilica, Belo Horizonte, v. 21, n. 1, p. 37-47, jan./mar. 2007. Disponível em: <http://dx.doi.org/10.1590/S0102-3306200700 0100005>. doi: 10.1590/S0102-33062007000100005. 
FORZZA, R. C.; COSTA, A. F da; WALTER, B. M. T.; BICUDO, C.; MOURA, C. W. N.; ZAPPI, D.; PERALTA, D. F. Lista de espécies da flora do Brasil. 2016.

Disponível em: <http://floradobrasil.jbrj.gov.br/>. Acesso em: 12 nov. 2016.

FREITAS, A. V. L.; COELHO, M. F. B.; MAIA, S. S. S.; AZEVEDO, R. A. B. Plantas medicinais: um estudo etnobotânico nos quintais do Sítio Cruz, São Miguel, Rio Grande do Norte, Brasil. Revista Brasileira de Biociências, Porto Alegre, v. 10, n. 1, p. 48-59, jan./março 2012. Disponível em: <http://www.ufrgs.br/seerbio/ojs/index.p hp/rbb/article/view/1833/1093>. Acesso em: 10 nov. 2016.

GONÇALVES, E. G.; LORENZI, H. Morfologia Vegetal: organografia e dicionário ilustrado de morfologia das plantas vasculares. v. 1. 2 ed. São Paulo: Instituto Plantarium de estudos da flora, 2011. 544 p.

IBGE. Estatísticas das cidades: Breu Branco, Pará. Instituto Brasileiro de Geografia Estatística, 2016. Disponível em: <http://cidades.ibge.gov.br/xtras/perfil.ph p?codmun=150178>. Acesso em: 17 dez. 2016.

LORENZI, H. Árvores Brasileiras: manual de identificação e cultivo de plantas arbóreas nativas do Brasil. v. 1. 6 ed. São Paulo: Instituto Plantarium de estudos da flora, 2014. 384 p.

MARTINS, S. V. Ecologia de florestas tropicais do Brasil. v. 1. 2 ed. Viçosa: UFV, 2012. $371 \mathrm{p}$.

MESSIAS, M. C. T. B.; MENEGATTO, M. F.; PRADO, A. C. C.; SANTOS, B. R.; GUIMARÃES, M. F. M. Uso popular de plantas medicinais e perfil socioeconômico dos usuários: um estudo em área urbana em Ouro Preto, MG, Brasil. Revista Brasileira de Plantas medicinais, Campinas, v. 17, n. 1, p. 76-104, jan. 2015. Disponível em: <http://dx.doi.org/ 10.1590/1983-084X/12_139>. doi: 10.1590/1983$084 \mathrm{X} / 12 \_139$.

MOBOT. Missouri Botanical Garden. 2016. Disponível em: <http://www.tropicos.or g>. Acesso em: 15 jul. 2016.

MOREIRA, R. de C. T.; COSTA, L. C. do B.; COSTA, R. C. S.; Abordagem etnobotânica acerca do uso de plantas medicinais na Vila Cachoeira, Ilhéus, Bahia, Brasil. Revista Acta Farmacêutica Bonaerense, Buenos Aires, v. 21, n. 3, p. 205211, jun. 2002. Disponível em: <http://www.latamjpharm.org/trabajos/21/3/LAJOP_21 3_3_1_L8H8YN8M78.pdf>. Acesso em: 10 jan. 2017.

MUELLER-DOMBOIS, D.; ELLENBERG, H. Aims and methods of vegetation ecology. v. 1. 1 ed. New York: Blackburn Press, 1974. 547 p.

OLIVEIRA, D. M. S.; LUCENA, E. M. P. O uso de plantas medicinais por moradores de Quixadá-Ceará. Revista Brasileira de Plantas medicinais, Campinas, v. 17, n. 3, p. 407-412, jul. 2015. Disponível em: <http://dx.doi.org/10.1590/1983-084X/13_0 95>. doi: 10.1590/1983-084X/13_095.

PDRS. Plano de desenvolvimento regional sustentável do lago de Tucuruí. Governo do estado do Pará, 2013. Disponível em: <http://www.mi.gov.br/c/document ENCICLOPÉDIA BIOSFERA, Centro Científico Conhecer - Goiânia, v.14 n.25; p.169 2017 
_library/get_file?uuid=0a6eac82-0b58-40bf-a60e-c80828c0ec90\&groupld=10157>. Ácesso em: 18 out. 2016.

SANTOS, F. R.; SANTOS, M. J. C. O uso de plantas medicinais mantidas em sistemas agroflorestais no âmbito da agricultura familiar. Revista Scientia Plena, Sergipe, v. 8, n. 4, p. 47-302, nov. 2012. Disponível em: <https://www.scientiaplena.o rg.br/sp/article/view/1432/698>. Acesso em: 06 jan. 2017.

SILVA, C. G.; MARINHO, M. G. V.; LUCENA, M. F. A.; COSTA, J. G. M. Levantamento etnobotânico de plantas medicinais em área de Caatinga na comunidade do Sítio Nazaré, município de Milagres, Ceará, Brasil. Revista Brasileira de Plantas medicinais, Campinas, v. 17, n. 1, p. 133-142, jan. 2015. Disponivel em: <http://dx.doi.org/ 10.1590/1983-084X/12_055>. doi: 10.1590/1983084X/12 055.

SIVIERO, A.; DELUNARDO, T. A.; HAVERROTH, M.; OLIVEIRA, L. C. de; MENDONÇA, A. M. S. Plantas medicinais em quintais urbanos Branco, Acre, Brasil. Revista Brasileira de Plantas medicinais, Botucatu, v. 14, n. 4, p. 598-610, dez. 2012. Disponível em: <http://www.scielo.br/pdf/rbpm/v14n4/05.pdf>. Acesso em: 18 out. 2016.

SOUZA, V. C.; LORENZI, H. Botânica Sistemática: guia ilustrado para identificação das famílias de fanerógamas nativas e exóticas no Brasil, baseado em APG III. v. 1. 3 ed. Nova Odessa: Instituto Plantarium de estudos da flora, 2012. 768 p.

VEIGA, J. B.; SCUDELLER, V. V. Etnobotânica e medicina popular no tratamento de malária e males associados na comunidade ribeirinha Julião - baixo Rio Negro (Amazônia Central). Revista Brasileira de Plantas medicinais, Campinas, v. 17, n. 4, p. 737-747, dez. 2015. Disponível em: <http://dx.doi.org/10.1590/1983-084X/14_0 39>. doi: 10.1590/1983-084X/14_039. 